\title{
Risk Management in Study Abroad: Lessons from the Wilderness
}

\author{
Mark A. Rit chie
}

Chiang Mai University, Thailand

International Sustainable Development Studies Institute, Kalamazoo College

\section{Introduction ${ }^{1}$}

The subject of risk in study abroad is timely. With terrorism, natural disasters, disease and other incidents reported daily in the media, the world "out there" seems to be an increasingly dangerous place. Study abroad administrators and program managers have to sort out real risk from perceived risk, keep up with current events and come up with systems for managing risk.

In the wilderness setting, managing risk is a central part of the endeavor. Climbers assess risk before starting on their chosen route, and reassess risk as they make progress. Managing the associated risks of wilderness travel or mountaineering is as important a skill as proficiency with protection equipment and techniques. Because of this, risk management is a part of the skill set of people traveling and working in the wilderness. Risk management is not left to the administrators and leaders of wilderness education programs; it is taught as a core part of the curriculum. Programs like those of the National Outdoor Leadership School (NOLS) put their students in situations where there is real risk, traveling in remote wilderness settings, crossing rivers, climbing mountains, and teach their students to manage risk as an integral part of their program.

Both study abroad and wilderness education share a common concern for participant safety and program integrity. Similar to wilderness education, the field of study abroad has to manage risk, both in program design and administration. This essay seeks to lay out some principles from the field of wilderness education and apply those to study abroad. It will discuss judgment and risk management, with a special emphasis on practical suggestions 
for programs and the study abroad field more generally. While this comes out of experience in risk management in developing countries, much of it can be applied to study abroad in industrialized countries. This essay is not intended to be a comprehensive literature review on risk management in study abroad or in wilderness education. Rather, its purpose is to share some of the experiences and lessons learned from wilderness education so that they may be put to use in risk management in study abroad.

\section{B a c kground}

This essay is informed by the context and academic focus of the International Sustainable Development Studies Institute program (ISDSI), an initiative of Kalamazoo College, based in Chiang Mai, Thailand. The ISDSI programs are a fusion of cross-cultural learning with outdoor experiential education. The academic core is focused on people, the environment and development, with deep immersion into local cultures and communities. ISDSI has developed "expedition field courses," which are month-long block courses (three-four per semester), exploring specific issues in depth: agroecology and sustainable farming, political ecology and watershed management, island cultures and ecologies, etc. A large part of the time these courses are in remote areas, such as villages, islands or other "non-traditional" study abroad locations. In addition to the academic focus, this requires competency in two areas: cross cultural skills (language, knowledge of local norms, etc.) as well as the expedition skills to travel safely (leadership, technical skills like backpacking or sea kayaking, etc.). This combination of elements led us to spend a great deal of time studying wilderness-based risk management and applying it to the different demands and context of study abroad. Even with urban-based courses, risk management is an important part of what we do, and an essential skill we, in turn, teach our students. In the fall of 2002 we worked with the National Outdoor Leadership School's Professional Training Institute on a risk management audit, which helped to refine and improve ISDSI's risk management plan and procedures.

\section{The Nature of Risk and Study Abroad}

What is risk? How do accidents happen? Priest and Gass (1997) argue that accidents occur when accident potential is realized. Accident 
Frontiers: The Interdisciplinary Journal of Study Abroad

potential is the overlap between environmental dangers (objective dangers, outside human control) and human dangers (subjective, or within human control). The probability of an accident "is greatly influenced by the relative strengths and numbers of dangers present, as well as the proactive, active and reactive countermeasures you take." (Priest and Gass, 1997, p. 88-89) It is the interaction between these objective and subjective factors which leads to accidents. In the wilderness this might be the combination of a steep snow slope and deteriorating weather (environmental dangers) with an inadequately equipped group (human dangers). In a study abroad situation, this could be seen in the environmental danger of being in a foreign city (driving in heavy traffic on the "wrong" side of the road) and the human danger of students not paying attention.

Wilderness programs cringe when their students go in for a "town day" or a resupply; those are some of the times of greatest risk exposure for their programs as objective and subjective dangers multiply. However, in study abroad, urban settings are where most students spend all, or most, of their time. Study abroad programs are, in a very real way, in a more difficult position than wilderness programs in terms of being able to control and manage risk, because they have less control over our students and there are more objective dangers.

The distinction between objective and subjective dangers is a useful one for study abroad, because it helps to identify where the risks are (environmental or human) and what the response should be (avoiding, removing or dealing with risk). Rather than lumping all "dangers" into one category, this distinction is useful for study abroad as it allows risk management plans to define and deal with very different types of dangers. Objective dangers need to be dealt with in a very different way from subjective dangers. While objective dangers (the risk of being in an urban area) may be dealt with in part by choice of location, subjective dangers are, in most cases, more under our control. We cannot make the objective danger of driving a motorcycle less, because we have no control over the traffic patterns in our city. We can, however, make and enforce rules which do not allow our students to drive motorcycles.

How then to assess risk and accident potential? A useful formula for thinking about risk comes from mountaineering. "You can look at risk assessment as a kind of formula. It can be helpful to think of it something like this: risk $=$ severity $\mathrm{x}$ probability $\mathrm{x}$ time. This simply means that your 
risk is multiplied when there is an increase in any of the three risk variables: the likely severity of any accident, the probability an accident will occur, and the length of time at risk." (Graydon and Hanson, 1997, p. 442)

This model allows us to analyze discreet elements of risk (severity, probability and time) which are often conflated. For example, this would tell us that the risk profile of a short versus long term study program is inherently different, due to the increase in the time variable. This is why one can "get away with" lots of short-term trips (reducing the time variable) even if the probability of an incident is high. This also points out how longer-term programs should be more careful in trying to reduce probability and/or severity since they significantly increase the time variable.

Risk management plans for study abroad, then, should take into account the interaction between objective and subjective dangers as well as the factors (severity, probability and time) that go into determining risk. For example, in a course studying urban issues, visiting a slum is of central importance: so that students can understand the distinct physical environment, and so that they may learn from slum residents about how they are organizing and working for a better future. Slums are not inherently dangerous: just because people are poor does not mean they are violent. However, there are risks. Taking the above formula for risk into account, we can plan our trips during the day (reducing the probability of an incident) and for relatively short periods of time. We can also reduce the probability of an incident by working with NGOs and people from the slums to know where to go and where not to go. Subjective dangers can be reduced through briefing students on proper dress and behavior while in the slum, and building relationships with people in the slums (so they are looking out for the well-being of our students).

An additional area of risk management with which study abroad must consider encompasses the very different values and expectations regarding avoiding risk of other cultures. If a program is operating in a culture where the dominate cultural belief is that "fate" determines outcomes (what is going to happen will happen regardless of what we do), then prevention will not be valued or practiced to the same extent as it might be in a culture where agency is given priority (we can influence the outcome of events by our actions). Some cultures may not place a value on proactive risk management, which will make the job of managing risk effectively in that context very difficult. If the program administrator 
Frontiers: The Interdisciplinary Journal of Study Abroad

comes from a culture where prevention is valued very highly (as in the US), but working in a culture where fate is seen as determining outcomes (as is the case in many Asian cultures), then the host culture itself is, in a sense, a subjective hazard. Our expectations about common risk-avoiding behavior (such as wearing a seat belt) should be carefully examined within the context of cross-cultural settings, as risk avoidance may not be valued where we are running our programs. The dangers of working in a culture like the US, where common wisdom tells us that we are one hundred percent the "masters of our fate" is left as an exercise to the reader!

\section{Leadership and Judgment}

"Leadership means timely, appropriate actions that guide and support your group to set and achieve realistic goals. Great leaders create an environment that inspires individuals and groups to achieve their full potential." (NOLS, 1999)

Central to good risk management plans are leaders who are capable of carrying them out. Leadership for study abroad groups is often not given much thought beyond who is available or next in line to direct a program ISDSI has found, however, that even a basic grasp of leadership skills can make a big difference in how successful the group is, as well as how safe the group is during its sojourn abroad. Often academic expertise or seniority, rather than leadership skills, determines who takes a study group abroad. That is unlikely to change, but training in leadership skills and judgment can help increase the safety of the group.

Consciously cultivating leadership skills in our staff, as well as teaching these skills to students, have contributed $g$ towards better risk management. The seven core leadership skills used by NOLS are a good starting point: expedition behavior, competence, communication, judgment and decision making, tolerance for adversity and uncertainty, self awareness, and vision and action (NOLS, 1999; Harvey, 1999).

Expedition behavior refers to being courteous and caring for each other in a group. For a good team of students or mountain climbers to work well together, they need good expedition behavior. This behavior needs to be modeled by the leaders and become normative for the group. In a wilderness setting this might mean the faster hikers stopping early and to brew 
hot cups of tea on a cold day for the slower members of the team. In study abroad, this might mean those students with a better grasp of the language working with students whose language skills are not as good to help them buy food in the market. It can be something as simple as helping someone to lift a heavy bag onto a bus. Expedition behavior, in short, are those actions and attitudes that keep a group working well together, the sometimes small but always significant acts that contribute to a good expedition.

Leadership competence refers to technical competence for the task at hand. Priest and Gass (p.76) identify three types of competencies that leaders need to have. "Generic competency" refers to skills necessary for all activities, such as first aid, trip planning, awareness, etc. "Metaskills" refers to areas that combine hard and soft skills, such as leadership style, problem solving, judgment and decision making, etc. In addition to these skills, leaders need to have "specific competencies" unique to the particular activities. While in wilderness education this might mean kayaking or rock climbing, in study abroad skills might include competency in the local language, ability and knowledge of local laws, transportation systems, host-university regulations, and other essentials of daily life.

For study abroad, perhaps the most important "competency" is cultural sensitivity and understanding, which directly leads to appropriate behavior in a culture. The more sensitive one is to the norms of a culture, the greater the likelihood that one will behave in culturally-appropriate ways. Cultural knowledge and sensitivity (or lack of the same) directly and indirectly influences the safety of the group in two ways. First, culturally-appropriate knowledge and behavior can help avoid potentially dangerous situations. Second, culturally-inappropriate behavior can, conversely, create an unsafe situation.

Cultural sensitivity, knowledge and behavior, or, "cultural competency," is necessary but not a sufficient condition for a safe study abroad program. Conversely, cultural incompetence can turn an otherwise safe situation into an unsafe one. In groups, there is a second level in which this occurs. The modeling of culturally competent or incompetent behavior becomes critical to the safety of students abroad, as students will look to their leader and model their own behavior after the leader's. If the modeling is not appropriate, when the students are on their own they may end up in potentially dangerous situations due to their cultural ignorance. Likewise, they may be in a safe situation and turn it into an unsafe one 
through cultural insensitivity. In other words, cultural sensitivity enables the group leader to safely lead his or her group, and by modeling culturally-appropriate behavior the leader enables the students to be safer when they are on their own in the host culture. Conversely, someone who is culturally insensitive is dangerous in two ways: directly when leading the group, and indirectly, when on his or her own.

Concerns over cultural competency do not just extend to Americans abroad. Study abroad programs often are led by local people and by experts from the host country. However, one cannot assume a citizen of the country will understand and be able to operate in a specific local culture. City people may have little understanding of village culture and may approach it with preconceptions and stereotypes. Likewise, people from one region of the country may not understand the culture or language in another, and members of ethnic-majority groups may not understand the culture or language of ethnic minorities.

The leadership skill of communication, the ability to communicate and listen, is often more difficult in the study abroad context than in a wilderness setting. Participants and leaders often use a second (or third) language, and even when they share a common language there may be regional or cultural differences in nuance, meaning and understanding. Not only are communications skills important within the group, in the context of study abroad good communication skills extend to the people and culture outside the group. Cultural differences also impact communication, because they influence behavior beyond words. For example, in Thai culture what is not said can be more important than what is said. Even someone fluent in the Thai language who does not understand the importance of what is left unsaid would have a hard time communicating and listening accurately. Thus, someone planning an excursion into the Thai countryside may be told things are fine, but what they are not told may be the key factor in deciding if the excursion is going to be safe or not. Recognizing this requires both cultural competency and good communication skills.

Judgment and decision making refer to using appropriate decision-making styles for the task at hand. "Decision making should reflect the gravity and urgency of the decision being made" (Harvey, 1999, p. 173). This means both how one makes a decision and, also, when a specific type of decision making is appropriate. For example, autocratic decision making 
may be appropriate in a crisis, but consensus-based decision making might be appropriate in other situations. Judgment and decision making require correct assessment of subjective and objective dangers. As discussed earlier, subjective and objective dangers can combine, and it is the job of study abroad leaders and administrators to recognize these combinations and guard against poor judgment.

"Judgment is something that can be learned, but only with reflection. Two people who go through the same experience will have two different results. The person who does not reflect on her experience will miss the opportunity to learn and develop her judgment. That person will make the same mistakes over and over and never develop the judgment it takes to be a good leader. The person who takes a moment after a consequential mistake to think things over and reflect on the lesson learned and seek input from outside sources will develop good judgment in a hurry." (Harvey, 1999, p. 173)

Another key leadership skill is tolerance for adversity and uncertainty, an ability to work under pressure, keep calm, not complain, and deal with the inherent stress of leading. Good leaders learn to endure and enjoy hard work and challenge, and "live in rhythm with what you cannot control; control what you can" (NOLS, 1999). As with cultural competency, this is a skill that can be modeled to our students, helping them to develop tolerance for situations I which they might be having a hard time and struggling. While in the wilderness this might mean keeping a positive attitude while hiking in a rainstorm, in study abroad this might extend to difficult travel situations, unclear expectations from host families and many of the aspects of cross-cultural immersion.

Two final leadership skills are self-awareness and vision and action. Self awareness means knowing your self and your reactions, your strengths and weaknesses. In the context of study abroad, self awareness can help a leader understand his or her limits, recognize fatigue, burn out, or when assistance is needed. Vision and action refer to knowing what needs to be done and how to do it, knowing where to go and how to get there. This can be enhanced in study abroad by careful pre-planning and program design. However, translating amorphous goals like "cultural competency" into practical "real" activities requires vision and 
Frontiers: The Interdisciplinary Journal of Study Abroad

action on the part of trip leaders and administrators.

Choosing a leader for a study abroad program is difficult. In addition to academic competency, a leader must be competent in basic leadership and risk management skills. How does the person deal with stress? Is she "cool headed" in a crisis? Does he get rattled easily? The ability to handle stress is, possibly, the most important factor in safe outcomes. Risk management plans are worthless if, in situations of high stress, one cannot execute those plans.

As Thai field staff are selected and trained for academic field studies, these leadership skills are kept in mind, and an effort is made to select people who exhibit theses skills, and, then, to train them to be competent. Another important skill is being able to listen and seek input from others. Recognition of one's own limits (a part of self-awareness) is also critical. In training field staff, some of the most important skills to master are learning to be calm in high-stress situations and being able to make rapid, accurate decisions under pressure. Orientation and Thai-American teambuilding exercises with our students often use rock climbing, a technical skill in which all of our staff are proficient. In addition to being able to lead students competently, this helps the team learn how to deal with stress, feel comfortable with complex systems, manage fears, and increase self confidence. Backpacking, kayaking and canoeing are other enabling skills necessary for our courses. While they are important in themselves, we have learned that added attention to these sorts of skills makes us more capable in other environments. While the skills demanded when leadclimbing an overhanging rock face are very different from those necessary when taking a group of students through an urban slum, the ability to think under pressure is invaluable in both contexts.

\section{Safety Countermeasures}

Risk management strategies can be grouped within what Priest and Gass describe as "safety countermeasures" (1997, p. 93). They describe three types of safety countermeasures that are useful in the face of both objective and subjective dangers. Proactive/primary measures are procedures carried out in advance, such as "reconnaissance trips," orientation, site pre-visits, training, and dissemination of written information. Active/secondary measures are actions during a program, as well as during 
an accident, such as first aid, evacuation, and the on-site recording of incidents. Reactive/tertiary measures are follow-up actions after an accident, investigations and final documentation. These can be extended beyond use in the wilderness into study abroad by focusing on pre-program, program and post-program procedures.

Proactive/pre-program measures involve preparing any documentation, policies and procedures before the start of the program. For example, specific procedures, known as "accepted field practices" (AFPs) or "standard operating procedures" need to be developed beforehand to ensure a consistent risk management plan. Our AFPs are constantly reviewed and revised as we use them; they are helpful in ensuring that everyone involved in the program knows what are, and are not, acceptable practices. These can be quite detailed, depending on the activity, but are in place so that field staff members understand what to do. For example, loading and unloading from a ferry onto smaller "long-tail" boats in the ocean can be done safely, but clear directions on what is OK (passing bags by hand) and what is not OK (jumping down into the smaller boat with a large backpack) need to be in place before one is in the situation. Often the process of writing the AFPs as a team is the most important part, because it helps staff members check each other's judgment and ensures that any inconsistencies with our overall risk management principles are identified. Having pre-written AFPs also ensure that staff members don't have to make up policies "on the spot" which may conflict with the larger risk management plan. The AFPs are also helpful in new situations because they provide examples in which we have already worked out what is, and is not, acceptable.

An important part of this pre-program risk management planning involves reconnaissance trips to field-study sites. When setting up a new course this can be an involved process, taking several days and involving a number of field staff members. Our trip-planning documentation includes writing down the state of available medical care, the condition of roads, local contacts, evacuation plans, photographing key sites, and a great deal of other relevant information. These trips also help in figuring out logistics and timing, as well as building and renewing relationships with people. We often have found that, as we are evaluating relative risks during a reconnaissance trip, we find ways of simplifying a field study so that the study becomes academically stronger and safer. Even in areas 
Frontiers: The Interdisciplinary Journal of Study Abroad

where we have been many times, at least some members of the staff team will go in advance of the students in order to see if anything has changed and if there are new risks or new resources.

Active procedures occur while a program is running and are based on the proactive work that we have completed. Two of the most useful are emergency cards and course logs. Each student is given a small laminated card with emergency phone numbers (U.S. consulate, resident director, etc.) and the name of an approved local hospital written in both Thai and English. Students are instructed to carry this with at all times. While students are in-country, all staff members carry cell phones, programmed to auto-forward if the person the student calls is not available. Having the cards provides peace of mind for the students, and we have found them very useful. We re-issue cards if we change location, so the emergency card for Chiang Mai is different than for Bangkok. These also have proven handy for students when they are traveling on their own, as they are able to go directly to a trusted hospital, if necessary.

Course logs are day-to-day records of the program kept by the leader or instructor. We have taken the basic format used at NOLS and adapted it to our specific needs. Course logs provide the instructor or leader of the group a chance to stop and record significant events during the day. They do not need to take a lot of time, but are they useful in terms of overall record keeping, and for helping program coordinators at the office incountry know what is going on in the different field courses. Important changes since the reconnaissance visit can be noted, concerns with specific students and other issues all have a place in the course logs. These will be key documents if a program decides to expel a student, as they document any problems or complaints. More important, they provide institutional memory, and allow us to keep tabs on any necessary changes in AFPs or other risk management related issues. The key to useful course logs is to keep them short and flexible so that they are not a burden to fill out.

In addition to course logs a designated leader (field staff) is responsible for filling out incident reports if someone is injured. Unlike wilderness education, our incident (cultural or accident incidents) and near miss reports (an event where a cultural incident or accident was narrowly averted) incorporate cultural "incidents" as well. For example, we might record an incident of a student someone offending a host family. A binder with 
all our documentation, including AFPs, evacuation procedures, emergency contact information and notes from the reconnaissance trip is carried by each group leader.

Reactive, or post-program procedures, assess how a completed course went, and include writing up any necessary reports as well as, and debriefing both students and staff. We review risk management procedures, note any necessary changes, revise and update AFPs, and begin the process of planning for the next course. Student and staff evaluations are a very important part of this process. Walking students through the program chronologically, and then involving the students in the evaluation and assessment, with the goal of improving the program, has been essential. Once students realize that we are serious about listening to their input (which we establish early on in debriefings during the course), they are invested as stakeholders in improving the programs. Some of the best ideas for field courses have come out of student debriefing and review. Likewise, reviewing a course and debriefing staff is critical, especially after a difficult student group or if there have been any incidents during the program. Having the course log to consult at debriefing is valuable, as we can recall together what happened on a course, and decide what went well and what may be improved.

\section{Medical Care and Training}

Assessing medical care in any country is critical, including local emergency services and hospitals. As study abroad professionals know, emergency services we take for granted in North America often do not exist in other countries. The "golden hour" after an accident is what traditional first aid and EMT courses are geared towards. This is the timeframe during which receiving medical attention after trauma is most critical. However, if one is operating in an environment where your students may be an hour or more away from medical care, then training in wilderness first aid could be an important part of risk management. Unlike traditional first aid courses, wilderness first aid teaches about stabilizing and transporting a victim and providing extended care beyond the "golden hour." Even in urban area, leaders and staff members should have basic first aid training at a level appropriate for the activity. ${ }^{2}$ Our standard is Wilderness First Aid (WFA) or Wilderness Advanced First Aid (WAFA) 
Frontiers: The Interdisciplinary Journal of Study Abroad

for all staff, with at least one person on remote courses certified as a Wilderness First Responder (WFR). These certifications are similar to the Red Cross First Aid designations but tailored specifically to the wilderness or remote environments. Each level of certification is standardized in the wilderness education industry, with WFR required for NOLS instructors and similar professionals (e.g. back country search and rescue). Each level includes increasing amounts of training and depth of knowledge regarding medical care and emergencies. (WFA is a 2-3 day course; WAFA is 5 days and WFR 10 days.) The courses focus on long term patient care, evacuation guidelines and extended care situations, getting increasingly in-depth with each level. Emphasis is on decision making and judgment, not the memorization of lists, and all use realistic scenarios as a part of the training.

While we carry an extensive medical kit with us, the key is, as always, good training more than fancy equipment.

\section{The Lure of Technology}

There are seductive enabling technologies which many programs consider purchasing in order to make things "safer." However, we have found that judgment and experience are more valuable than equipment and gear. Just as some backcountry travelers assume a cell phone can get them out of trouble (and as a result of this thinking take greater risks), we do not assume advanced telecommunications or other equipment will be of use in a crisis. While we carry satellite phones, global positioning systems, digital cell phones, radios and other equipment as necessary, our risk management plan includes contingencies in case the technology fails. All of these things can augment a risk management plan, but they are not substitutes for a well-trained team and a clear understanding on the limitations of the equipment. We have learned not to be dependent on equipment but to be prepared to improvise and "make do" with what we have. Gear breaks and batteries go dead. It is easy to think that once you've bought a satellite phone, things will be safer. However, whom are you going to call? Do you have an agreement with a helicopter medical-evacuation service or the local military? While technology is helpful, it has to fit within a wider risk management plan to be of use. 
M a r A. Rit chi e

\section{Sharing the Risk Management Process with Students}

The goal of study abroad is not merely to lead students through a foreign country, but to teach them to be competent to live, work and travel in a very different setting. Study abroad can, like wilderness education, better equip students to be independent by teaching risk management principles as a part of its program. This can be done through concepts such as "leader of the day," in which a student shares leadership tasks with the staff team, as well as through opening up decision making and assessments to the students where appropriate.

Sharing the reasons behind risk management decisions is important for student safety. "[T] The leader of an inexperienced party may mentally conduct a flawless evaluation of a hazard and determine that conditions are safe. But unless the leader shares the thinking that went into this decision, the members of the party may falsely assume that similar situations are always without hazard." (Graydon and Henson, 1997, p. 443) We miss an important teaching opportunity if we do not share the reasons for risk management decisions with students while leading them. Obviously, not all risk management decision processes need to be, or should be, shared with students. However, as we have shared appropriate decision making with students, we have found that students become more competent, skilled and reliable. For example, working with the students through a structured decision making tree while deciding on the next days activities in a village helps the students to know more about what is going on, and to understand how to make decisions when they are on their own.

The "leader of the day" has been invaluable in terms of increasing the ability of students to be active learners and also in helping to better manage the group. Each student takes their turn being in charge of the group logistics for a day, sometimes in pairs, which further facilitates team-building. Using "leader of the day" not only makes our job easier (we are not the one herding students onto the bus!) but it also helps all the students become better followers. Last year, during a debriefing with the students, the two students who had been leaders of the day decided that they were going to require that all of the students wear watches so they would not be late to events. We didn't have to nag the students about 
Frontiers: The Interdisciplinary Journal of Study Abroad

being on time; their peers in leadership positions could see the impact of people being late, and move to correct the situation.

Both students and faculty can get into, and out of, potentially dangerous situations. And, as a result of no harm coming to them, it can be difficult for program leaders, to know what is, and what is not, a dangerous situation. Over time, this increases the risk exposure of a program. "You can be misled into accepting dangerous levels of risk by simple phenomenon that might be termed nonevent feedback: nothing bad happened last time; therefore, nothing bad will happen this time. Nonevent feedback occurs when we do not experience the potential consequences of our actions" (Graydon and Hanson, 1997, p. 443). Nonevent feedback usually is applied to situations where someone engages in dangerous behavior and gets away with it, such as crossing an avalanche-prone slope, but not triggering an avalanche. Each time there is a "nonevent," the person is lead to believe that the behavior is safe, when in fact it is not. Students studying abroad (as well as on the home campus) often are part of nonevent feedback loops, where they unknowingly engage in behavior that is dangerous, but for some reason nothing happens. Opening up the risk management process to students by debriefing, especially after a "critical incident" where something has gone wrong or there was a near miss, is crucial to helping students overcome the dangers of the "nonevent feedback" that they often experience.

Sharing the risk management process with students has helped them to understand how to assess risk, develop contingency plans, make good decisions, and how to learn safely and effectively in a new culture. We work with students throughout the semester. When the end of semester break comes, we require students to apply what they have learned: they are mentored by our field staff and are required to write risk-management plans for when they are on break. For example, students planning to travel to Southern Thailand by boat had to think through, and write up, what they would do if the boat was over-crowded, how they would check for life jackets, and what they would do in an emergency. On their return from break, students excitedly shared how their risk management plans kept them from getting into possibly dangerous situations, and how the plans made their travels easier, since they didn't have to "make things up on the spot." Instead they were guided by their planning. This experience positively impacted the students' academic program. In the second semester, 
MarkA. Ritchie

when these students started their internships, they were well prepared to be independent and responsible learners.

\section{Conclusion}

Many people perceive rock climbing as a high-risk activity. However, as borne out in accident statistics and analysis of person-hours per activity, there is a much higher risk of being killed or injured on the drive to the cliff than during the actual climb. We perceive traveling at high speeds in vehicles as "low risk" because we do it every day as a necessary part of our lives, with nonevent feedback reinforcing the idea that cars are "safe." Rock climbing, however, is not a routine activity, and for someone unfamiliar with the modern safety and protection systems that are a part of rock climbing, it seems like a dangerous thing to do.

So too with study abroad. Some people perceive that any trip abroad is "dangerous," while ignoring the high levels of crime in many regions of North America. Many study abroad programs are located in areas, such as Europe, with a lower perceived risk than programs in developing countries. However, we do not know if this is an accurate perception or not, since there is little sharing of data or statistics about incidents, near-misses and accidents in study abroad. The outdoor and wilderness-education field is far ahead of the study abroad field in recording, publishing and sharing risk and incident data. We know, for example, accident rates in rock climbing or other wilderness activities, because records are kept and information is shared. In wilderness education, an annual conference on wilderness risk management is held, incidents and accidents are analyzed, data is shared, and the field as a whole is becoming safer and more effective at understanding risk. ${ }^{3}$ For example, data shows that accidents are more likely to occur at certain times of day (due to fatigue and other factors). Incorporating this into program planning has allowed wilderness programs to reduce incidents.

The strategies discussed above are useful for managing risk for an individual program. However, having every study abroad program engaged in risk management best practices will not be useful to field of study abroad as a whole unless we share information. The study abroad field needs to begin to share information, promote standard ways of reporting accidents, incidents and near misses, and share how we each manage the 
Frontiers: The Interdisciplinary Journal of Study Abroad

risk in our programs. Only by being open, by sharing our risk management techniques, successes and failures, can we make study abroad safer.

\section{Notes}

${ }^{1}$ I would like to thank Araya Kruangkum, Kanokrot Sukkasem, Jakkrit Sangkhamanee, Eric Boggs, Jessica Roder and the rest of the ISDSI team for their excellent work developing and ground testing our risk management plan. Special thanks to Molly Doran, Missy White and the rest of the people at the National Outdoor Leadership School's Professional Training Institute (www.nols.edu/pti/) for their assistance in risk management and program design.

${ }^{2}$ The Wilderness Medical Institute (www.nols.edu/wmi/) runs training programs across the United States. They can help you decide what level of medical training is appropriate for the conditions you operate in, and can design custom courses tailored to your specific needs.

${ }^{3}$ The annual Wilderness Risk Management Conference (www.nols.edu/pti/wrmc/) is jointly sponsored by NOLS, Outward Bound and SCA. In addition to wilderness risks, legal issues, medical concerns and risk management principles are covered in both conference sessions and hands-on workshops. Much of what is covered is directly applicable to study abroad. Their conference proceedings are an invaluable source of information for people interested in learning more about risk management.

\section{References}

Graydon, Don and Kurt Hanson, Mountaineering: The Freedom of the Hills. Seattle: The Mountaineers. 1997.

Harvey, Mark. The National Outdoor Leadership School's Wilderness Guide. Fireside, 1999.

National Outdoor Leadership School. Leadership at NOLS. Lander: NOLS. 1999.

Priest, Simon and Michael Gass. Effective Leadership in Adventure Programming. University of New Hampshire: Human Kinetics. 1997. 